\title{
Detection of Bacteraemia in an Inadequate Volume of Blood
}

\author{
AISHA M. SidDIQUI, MRCP(UK)* AHMAD T. ElTAHAWY, MBBCh, MSC, PhD**, and \\ AHMAD A. BAHNASSY, MSC, MSPH*** \\ ${ }^{*}$ Department of Medicine, ${ }^{* *}$ Department of Microbiology, and ${ }^{* * *}$ Department \\ of Community Medicine, Faculty of Medicine \& Allied Sciences, \\ King Abdulaziz University, Jeddah, Saudi Arabia
}

\begin{abstract}
It was recently discovered that $15 \%$ of adult blood culture specimens at King Abdulaziz University Hospital were inadequate in volume where only $2 \mathrm{ml}$ were collected instead of the required $8 \mathrm{ml}$ using the Signal oxoid medium. A comparison of 263 matched pairs of standard-volume $(8 \mathrm{ml})$ and low-volume $(2 \mathrm{ml})$ blood cultures from adult patients in the medical ward and intensive care unit at King Abdulaziz University Hospital showed that standard-volume cultures had a higher detection rate for bloodstream infection than did low-volume cultures (89\% compared with 69\%; difference: $20 \%, \mathrm{P}=0.01$ ). Our data show that the yield of blood cultures in adults increases approximately $3.3 \%$ per millilitre of blood cultured, and that the sensitivity of the standardvolume cultures is statistically higher than the sensitivity of the low-volume cultures $(84 \%$ vs. $65 \%, \mathrm{P}<0.01)$.
\end{abstract}

Keywords: Blood, Blood culture, Bacteraemia

\section{Introduction}

To guide management of Septicaemia, clinicians understandably expect blood-culturing practices to be sensitive for the detection of Bacteraemia and Candidemia. The volume of blood drawn in adult patients is the most important single factor governing the sensitivity of blood cultures ${ }^{[1-9]}$, and 10 to $20 \mathrm{ml}$ of blood per draw has been recommended $^{[4,6,10-12]}$.

Correspondence \& reprint requests to: Dr. A. Siddiqui, P.O. Box 80215, Jeddah 21589, Saudi Arabia. Accepted for Publication: 15 December 1998. Received: 6 May 1998 
This recommendation is based on studies showing that during bloodstream infections, especially those in adults, there may be relatively few microorganisms present in a given volume of blood often in the range of $<1-10$ colony forming unit (CFU) per millilitre ${ }^{[10,13,14]}$. Moreover, in numerous studies of adult patients, a direct relationship between the diagnostic yield of blood cultures and the volume of blood cultured has been documented ${ }^{[10]}$. It was discovered that $15 \%$ of adult blood culture specimens at King Abdulaziz University Hospital were inadequate in volume where only $2 \mathrm{ml}$ were collected instead of the required $8 \mathrm{ml}$ necessary to have a $10 \%$ dilution of blood with the culture media used, according to the requirements ${ }^{[15-17]}$. Concerned that the low volumes of cultured blood might be compromising the sensitivity of blood cultures for detection of Bacteraemia in our adult patients, we studied the yield of low volume of blood used in culture media $(2 \mathrm{ml})$ in comparison with adequate volume of blood $(8 \mathrm{ml})$ in our adult patients in the medical ward and intensive care unit.

\section{Materials and Methods}

Blood specimens were collected from adult inpatients who had a temperature > $38.5^{\circ} \mathrm{C}$ or showed signs of Septicaemia. A standard-volume of blood culture specimen was defined as $8 \mathrm{ml}$ of blood, and a low-volume specimen was defined as $2 \mathrm{ml}$ of blood. Blood specimens were collected from peripheral veins using a strict aseptic technique and sterile equipment. The specimens were inoculated into the blood culture bottles, mixed with the medium, and incubated at $37^{\circ} \mathrm{C}$ for 7 days.

The medium was signal blood culture system (Oxoid) which was formulated to encourage growth of Aerobic, Anaerobic, and Microaerophilic organisms. It contained $80 \mathrm{ml}$ of brain heart infusion broth and thioglycollate broth. Blood was injected aseptically through the central ring of the rubber stopper (a volume of $8 \mathrm{ml}$ of blood was recommended by the manufacturer). The medium was designed to create pressure in the sealed bottle when organism growth is present. The medium did not contain any antibiotic removal device. To avoid contamination, no attempt was made to add such device to the culture medium. The presence of a positive pressure causes a quantity of the blood/broth mixture to be moved into the growth indicator chambre which is connected to the bottle after the blood specimen was added. A positive result is indicated when the blood/broth mixture rises above the green locking sleeve of the growth indicator device. Smears of the blood/broth were stained with gram stain and culture was done on to blood and chocolate agar plates. The isolated organisms were identified using standard methods ${ }^{[18]}$. Gram-negative rods were identified using API 20 (Analytab).

\section{Results}

A total of 263 matched pairs of standard-volume $(8 \mathrm{ml})$ and low-volume $(2 \mathrm{ml})$ blood cultures were done. One hundred and sixty-nine (169) cases were males $(64 \%)$, while 94 cases were female $(36 \%)$. The nationality of the patients were: 113 Saudi 
(43\%) and 150 non-Saudi (57\%). The mean age was 46 years \pm 20 .

Of the 263 matched pairs blood cultures, 36 (13.6\%) were positive and $227(86.4 \%)$ were negative. As shown in Table $1,89 \%$ of the 36 positive blood cultures were detected by standard-volume cultures, whereas $69 \%$ were detected by low-volume cultures, a difference in the yield of $20 \%(\mathrm{P}=0.01)$.

TABLE 1. Yield of standard and low volume blood cultures in 36 positive bloodstream infections.

\begin{tabular}{|c|c|c|c|c|c|c|}
\hline \multirow{2}{*}{} & \multicolumn{3}{|c|}{ Classification of bloodstream pathogens } \\
\cline { 2 - 7 } & Gram positive & Gram negative & \multicolumn{3}{c|}{ Total } \\
\hline Variable & No. & $\%$ & No & $\%$ & No & $\%$ \\
\hline Organisms detected by standard volume cultures & $16 / 18$ & 89 & $16 / 18$ & 89 & $32 / 36$ & $89 *$ \\
\hline Organisms detected by low volume cultures & $13 / 18$ & 72 & $12 / 18$ & 67 & $25 / 36$ & 69 \\
\hline
\end{tabular}

$8 \mathrm{ml}$ (CI $89 \%, 0.79$ to 0.99$)$

$2 \mathrm{ml}$ (CI $69 \%, 0.53$ to 0.84$)$

$* \mathrm{P}=0.01$

The respective sensitivities and specificities of standard and low-volume blood cultures in the detection of Bacteraemia is presented in Table 2. The standard-volume method had a fairly good sensitivity as it detected $84 \%$ from the positive cases and a high specificity where it detected $95.4 \%$ of the normal cases. The sensitivity of the low-volume method is significantly lower than that of the standard volume--65.6\% vs. $84 \%(\mathrm{P}=<0.01)$.

TABLE 2. Sensitivity and specificity of the standard- and low-volume blood cultures.

\begin{tabular}{|c|c|c|c|}
\hline & \multicolumn{3}{|c|}{ Low volume blood culture $(2 \mathrm{ml})$} \\
\hline & Positive & Negative & Total \\
\hline \multicolumn{4}{|l|}{ Standard volume blood culture } \\
\hline positive & 21 & 11 & 32 \\
\hline negative & 4 & 227 & 231 \\
\hline Total & 25 & 238 & 263 \\
\hline
\end{tabular}

Sensitivity of $8 \mathrm{ml}=21 / 25=84 \%$

Specificity of $8 \mathrm{ml}=227 / 238=95.38 \%$

On the other hand, the low-volume culture showed a higher specificity than that of the standard-volume (98.3\% vs. $95.4 \%$, respectively), but this difference is not statistically significant $(\mathrm{P}=>0.05)$.

Table 3 shows the list of the organisms by the species isolated from the blood cultures by each method. Anaerobes and yeasts were not isolated during the study period. Only 49 patients (19\%) had clinical evidence of Septicaemia; 97 (37\%) of the patients were on concomitant antibiotics. More than $85 \%$ of the cases had abnormal CBC, renal and liver function tests. The number of isolates were nearly similar in both culture 
methods, but the standard-volume detected more organisms in patients with malignancies, congestive cardiac failure, and urinary tract infections (Table 4). Approximately $25 \%$ of the blood cultures were from diabetics.

TABLE 3. The species of microorganisms isolated from the blood culture by each method

\begin{tabular}{|l|c|c|}
\hline \multicolumn{1}{|c|}{ Species } & $\begin{array}{c}2 \mathrm{ml} \text { method } \\
(\mathrm{n}=25)\end{array}$ & $\begin{array}{c}8 \mathrm{ml} \text { method } \\
(\mathrm{n}=32)\end{array}$ \\
\hline Coagulate-negative staphylococci & 5 & 6 \\
\hline Staphylococcus aureus & 6 & 1 \\
\hline Streptococcus pneumoniae & 1 & 1 \\
\hline Streptococcus morbillorum & 1 & 6 \\
\hline Escherichia coli & 2 & 1 \\
\hline Klebsiella pneumoniae & 5 & 1 \\
\hline Enterobacter cloacae & 1 & 2 \\
\hline Pseudomonas aeruginosa & 1 & 2 \\
\hline Salmonella typhi & 1 & 1 \\
\hline Salmonella species & 1 & \\
\hline Vibrio cholerae non 0 1 & 1 & \\
\hline
\end{tabular}

TABLE 4. Number of positive blood cultures detected by both methods according to underlying diseases.

\begin{tabular}{|l|c|c|c|c|c|r|}
\hline \multicolumn{1}{|c|}{ Underlying diagnosis } & $\begin{array}{c}\text { Total no. } \\
\text { of cultures }\end{array}$ & $\%$ & $\begin{array}{c}\text { +ve no. of } \\
\text { cultures by 2 ml }\end{array}$ & $\%$ & $\begin{array}{c}\text { +ve no. of } \\
\text { cultures by } 8 \mathrm{ml}\end{array}$ & $\%$ \\
\hline Malignancy & 40 & 15.2 & 2 & 5.0 & 4 & 10.0 \\
\hline Diabetes mellitus & 63 & 24.0 & 11 & 17.5 & 10 & 15.9 \\
\hline Ischemic heart disease & 27 & 10.3 & 3 & 11.1 & 3 & 11.1 \\
\hline Congestive cardiac failure & 8 & 3.0 & 1 & 12.5 & 8 & 100.0 \\
\hline Bronchial asthma & 11 & 4.2 & 2 & 18.2 & 1 & 9.1 \\
\hline Chest infection & 42 & 16.0 & 4 & 9.5 & 4 & 9.5 \\
\hline Urinary tract infection & 21 & 8.0 & 1 & 4.8 & 2 & 9.5 \\
\hline Others* & 51 & 19.3 & 1 & 2.0 & 0 & 0.0 \\
\hline
\end{tabular}

*Examples:

Skin infections

Eye infections

Hypertension

Connective tissue diseases

Thyroid diseases

It was noticed that many patients had multiple underlying diseases, sources of infection, and multiple blood cultures. Intravenous cannulas, the gastrointestinal tract, and the respiratory tract, in this order, were the main sources of positive blood cultures by the two methods (Table 5). The source of Bacteraemia in the majority of the patients was determined microbiologically. 
TABLE 5. Number of positive blood cultures detected by both methods according to source of infection.

\begin{tabular}{|l|c|c|c|c|c|r|}
\hline \multicolumn{1}{|c|}{ Source of infection } & $\begin{array}{c}\text { Total no. } \\
\text { of cultures }\end{array}$ & $\%$ & $\begin{array}{c}\text { +ve no. of } \\
\text { cultures by } 2 \mathrm{ml}\end{array}$ & $\%$ & $\begin{array}{c}\text { +ve no. of } \\
\text { cultures by } 8 \mathrm{ml}\end{array}$ & $\%$ \\
\hline Urinary tract & 18 & 18.0 & 2 & 11.1 & 2 & 11.1 \\
\hline Gastrointestinal tract & 4 & 1.5 & 4 & 100.0 & 4 & 100.0 \\
\hline Respiratory tract & 25 & 25.0 & 3 & 12.1 & 2 & 8.0 \\
\hline Intravenous cannula & 19 & 7.2 & 16 & 84.2 & 19 & 100.0 \\
\hline Others* & 72 & --- & --- & --- & 5 & 6.9 \\
\hline
\end{tabular}

*Examples: Skin infections, Eye infections, Ear infections, Throat infections.

\section{Discussion}

The yield of blood cultures from adults is clearly volume-dependent ${ }^{[1-9]}$ and increases approximately $3 \%$ for each additional millilitre of blood obtained ${ }^{[3-4]}$. We found an increased yield of approximately $3.3 \%$ per millilitre in our study. The percentage of positive blood culture in our study (13.6\%) compares favorably with the $11 \%$ reported by Li et al ${ }^{[19]}$. Because about $15 \%$ of adult blood cultures in our hospital contained inappropriately low volumes of blood, and as has been proven in our study, we believe that a substantial number of bloodstream infections were reported negative.

The result of this study emphasizes the role of the microbiology laboratory in clinician education where few clinicians or nurses are aware of the prime importance of the volume of blood cultured per set for the successful detection of Bacteraemia or Fungemia in adult patients.

We conclude that in our study, the blood culture yield is largely volume-dependent and that the difference in the sensitivity between standard-volume and low-volume cultures is statistically significant.

\section{References}

[1] Henry NK, McLimans CA, Wright AJ, Thompson RL, Wilson WR, Washington JA 2d. Microbiological and clinical evaluation of the ISOLATOR lysis centrifugation blood culture tube. J Clin Microbiol 1983; 17(5): 864-869.

[2] Koontz FP, Flint KK, Reynolds JK, Allen SD. Multicenter comparison of the high volume (10 ml) NR BACTEC PLUS system and the standard (5 ml) NR BACTEC system. Diagn Microbiol Infect Dis 1991; 14(2): 111-118.

[3] Mermel LA, Maki DG. Detection of Bacteremia in adults: consequences of culturing an inadequate volume of blood. Ann Intern Med 1993; 119(4): 270-272.

[4] Hall MM, Ilstrup DM, Washington JA 2d. Effect of volume of blood cultured on detection of Bacteremia. J Clin Microbiol 1976; 3(6): 643-645.

[5] Shanson DC, Thomas F, Wilson D. Effect of volume of blood cultured on detection of Strepcoccus viridans bacteraemia. J Clin Pathol 1984; 37(5): 568-570.

[6] Aronson MD, Bor DH. Blood cultures. Ann Intern Med 1987; 106(2): 246-253.

[7] Tenney JH, Reller B, Mirrett S, Wang W, Weintein MP. Controlled evaluation of the volume of blood cultured in detection of Bacteremia and Fungemia. J Clin Microbiol 1982; 15: 558-561.

[8] Kellogg JA, Manzella JP, McConville JH. Clinical laboratory comparison of the $10 \mathrm{ml}$ isolator 
blood culture system with BACTEC radiometric blood culture media. J Clin Microbiol 1984; 20(4): 618-623.

[9] Werner AS, Cobbs CG, Kaye D, Hook EW. Studies on the Bacteremia of Bacterial endocarditis. JAMA 1967; 202(3): 199-203.

[10] Plorde JJ, Tenover FC, Carlson LG. Specimen volume versus yield in the BACTEC blood culture system. J Clin Microbiol 1985; 22(2): 292-295.

[11] Washington JA 2d, Ilstrup DM. Blood cultures: issues and controversies. Rev Infect Dis 1986; 8: 792-802.

[12] Strand CL, Shulman JA. Blood stream infections: laboratory detection and clinical considerations. Chicago:ASCP Press, 1988; 7-14.

[13] Dorn GL, Burson GG, Haynes JR. Blood culture technique based on centrifugation: clinical evaluation. J Clin Microbiol 1976; 3(3): 258-263.

[14] Telenti A, Steckelberg JM, Stockman L, Edson RS, Roberts GD. Quantitative blood cultures in Candidemia. Mayo Clin Proc 1991; 66(11): 1120-1123.

[15] Aukenthaler R, Ilstrup DM, Washington JA 2d. Comparison of recovery of organisms from blood cultures diluted 10\% (volume/volume) and 20\% (volume/volume). J Clin Microbiol 1982; 15: 860864.

[16] Bartlett RC, Ellner PD, Washington JA 2d. 1974. Cumitech I, blood cultures. Coordinating ed., Sherris JC. Am Soc for Microbiol, Washington, D.C.

[17] Ilstrup DM, Washington JA 2d. The importance of volume of blood cultured in the detection of Bacteremia and Fungemia. Diagn Microbiol Infect Dis 1983; 1(2): 107-110.

[18] Cowan ST, Steel KJ. Manual for the identification of medical bacteria. London: Cambridge University Press 1970: 47-56, 103-117.

[19] Li J, Plorde JJ, Carlson LG. Effect of volume and periodicity on blood cultures. J Clin Microbiol 1994; 32: 2829-2831. 


\section{وجود التجرثم بكميات قليلة في مقدار الدم}

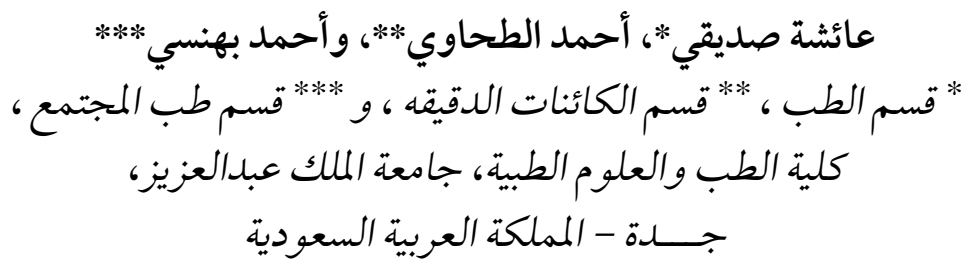

المستخلص. اكتشف مؤخراً أن 0 1\% من عينات مزرعة الدم للبالغين

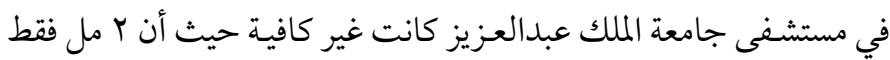

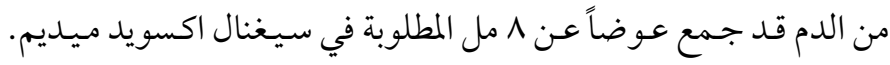

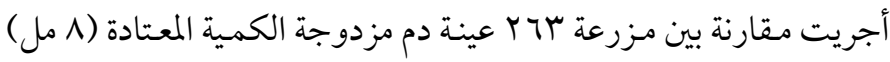
وكمية أقل (r مل ) من مرضى بالغين منومين في عنبر الأمراض الباطنة

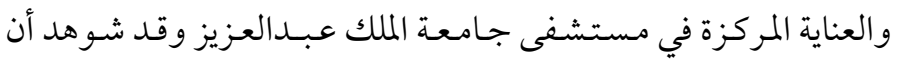

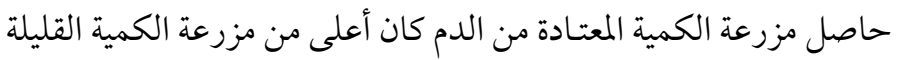

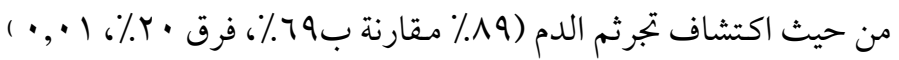

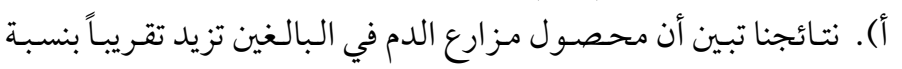

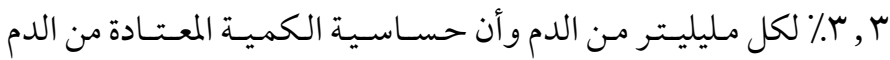

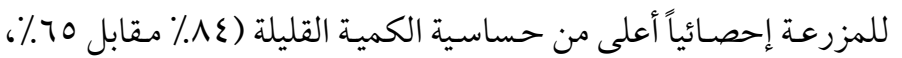
(أ) 